University of Wollongong

Research Online

Australian Institute for Innovative Materials -

Papers

Australian Institute for Innovative Materials

2006

Efficient dye sensitized solar cells based on a 2-thiophen-2-yl-vinylconjugated ruthenium photosensitizer and a conjugated polymer hole conductor

Attila Mozer

University of Wollongong, attila@uow.edu.au

Y Wada

Osaka University

K-J Jiang

Shimane Institute for Industrial Technology

N Masaki

Osaka University

S Yanagida

Osaka University

See next page for additional authors

Follow this and additional works at: https://ro.uow.edu.au/aiimpapers

Part of the Engineering Commons, and the Physical Sciences and Mathematics Commons

Research Online is the open access institutional repository for the University of Wollongong. For further information contact the UOW Library: research-pubs@uow.edu.au 


\title{
Efficient dye sensitized solar cells based on a 2-thiophen-2-yl-vinyl-conjugated ruthenium photosensitizer and a conjugated polymer hole conductor
}

\author{
Abstract \\ Efficient dye-sensitized $\mathrm{TiO}_{2}$ solar cells based on a 2-thiophen-2-yl-vinyl-conjugated ruthenium \\ photosensitizer and a conjugated polymer poly(3,4-ethylenedioxythiophene) have been fabricated. A \\ maximum power conversion efficiency of $2.6 \%$ is achieved when the mesoporous $\mathrm{TiO}_{2}$ layer is $5-6 \mu \mathrm{m}$. \\ The high fill factor $(0.74)$, the open circuit voltage $(0.78 \mathrm{~V})$, and the linear light intensity dependence of the \\ short circuit current density $\left(4.5 \mathrm{~mA} \mathrm{~cm}^{-2}\right.$ at $\left.100 \mathrm{~mW} \mathrm{~cm}^{-2}\right)$ make these devices promising for solid state \\ photovoltaic applications.

\section{Keywords} \\ 2, cells, solar, sensitized, hole, polymer, photosensitizer, conjugated, yl, thiophen, conductor, dye, efficient, \\ ruthenium, vinyl \\ Disciplines \\ Engineering | Physical Sciences and Mathematics

\section{Publication Details} \\ Mozer, A. J., Wada, Y., Jiang, K., Masaki, N., Yanagida, S. \& Mori, S. N. (2006). Efficient dye sensitized solar \\ cells based on a 2-thiophen-2-yl-vinyl-conjugated ruthenium photosensitizer and a conjugated polymer \\ hole conductor. Applied Physics Letters, 89 (043509), 1-3.
}

\section{Authors}

Attila Mozer, Y Wada, K-J Jiang, N Masaki, S Yanagida, and Shogo Mori 


\title{
Efficient dye-sensitized solar cells based on a 2-thiophen-2-yl-vinyl- conjugated ruthenium photosensitizer and a conjugated polymer hole conductor
}

\author{
A. J. Mozer ${ }^{a)}$ and Y. Wada \\ Material and Life Science, Graduate School of Engineering, Osaka University, Suita 565-0871, Japan \\ K.-J. Jiang \\ Shimane Institute for Industrial Technology, Matsue, Shimane 690-0816, Japan
}

N. Masaki and S. Yanagida ${ }^{\text {b) }}$

Center for Advanced Science and Innovation, Osaka University, Suita 565-0871, Japan

\begin{abstract}
S. N. Mori
Department of Fine Materials Engineering, Faculty of Textile Science and Technology, Shinshu University, Ueda 386-8567, Japan
\end{abstract}

(Received 22 March 2006; accepted 26 June 2006; published online 27 July 2006)

\begin{abstract}
Efficient dye-sensitized $\mathrm{TiO}_{2}$ solar cells based on a 2-thiophen-2-yl-vinyl-conjugated ruthenium photosensitizer and a conjugated polymer poly(3,4-ethylenedioxythiophene) have been fabricated. A maximum power conversion efficiency of $2.6 \%$ is achieved when the mesoporous $\mathrm{TiO}_{2}$ layer is 5-6 $\mu \mathrm{m}$. The high fill factor $(0.74)$, the open circuit voltage $(0.78 \mathrm{~V})$, and the linear light intensity dependence of the short circuit current density $\left(4.5 \mathrm{~mA} \mathrm{~cm}{ }^{-2}\right.$ at $\left.100 \mathrm{~mW} \mathrm{~cm}^{-2}\right)$ make these devices promising for solid state photovoltaic applications. () 2006 American Institute of Physics.
\end{abstract}

[DOI: $10.1063 / 1.2240296$ ]

Dye-sensitized solar cells (DSCs) are developed for high efficiency, cost effective applications of solar to electrical power conversion. ${ }^{1}$ The most efficient systems use a nanostructured $\mathrm{TiO}_{2}$ electrode with a large surface area and a photosensitizer chemically adsorbed on its surface. Light absorption by the photosensitizer results in electron injection to the conduction band of the $\mathrm{TiO}_{2}$ with high quantum yield. The photo-oxidized dye is then reduced by the iodide/triiodide $\left(I^{-} / I_{3}^{-}\right)$redox couple dissolved in an organic electrolyte. Attempts to solidify and thus improve the operational stability of DSCs include the replacement of the organic electrolyte by low volatile compounds such as polymer electrolytes, ${ }^{2}$ ionic liquids, ${ }^{3}$ or ionic liquid crystals. ${ }^{4}$

A series of solid organic hole conductors ${ }^{5}$ and electroactive conjugated polymers ${ }^{6}$ has also been used. The best performance of these solid DSCs is around 4\%, achieved using an amphiphilic ruthenium dye in combination with a small molecule hole conductor spiro-MeOTAD. ${ }^{7}$ The key issues towards high performance are the complete wetting of the dye covered $\mathrm{TiO}_{2}$ surface as well as the filling of the voids of the mesoporous electrode by the hole conducting medium. ${ }^{5}$

An elegant route is to photoelectrochemically synthesize a conjugated polymer within the pores of the $\mathrm{TiO}_{2}$ electrode. ${ }^{6}$ This photopolymerization process is initiated by the photoexcitation of the ruthenium dye, by default leading to close contact of photosensitizer and the hole conducting polymer. This crucial interface can be further improved by the design of new photosensitizer dyes containing side groups compatible with the hole conducting conjugated polymer. Herein we report efficient solid state DSCs using a ruthenium dye containing a 2-thiophen-2-yl-vinyl-conjugated bipyridyl ligand and poly(3,4-ethylenedioxythiophene)

\footnotetext{
a)Electronic mail: attila@uow.edu.au

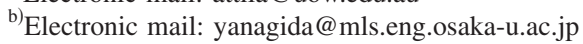

(PEDOT) following the above principle. The thickness of the mesoporous $\mathrm{TiO}_{2}$ layer of the DSCs is varied, and the highest efficiency of $2.6 \%$ at $5.8 \mu \mathrm{m}$ thickness is obtained.

The multilayer structure of the devices illustrated in the inset of Fig. 1 consists of (1) a F-doped $\mathrm{SnO}_{2}$-coated glass substrate (FTO, $10 \Omega / \square$, Nippon Sheet Glass), (2) a compact $\mathrm{TiO}_{2}$ layer deposited following the procedure described in Ref. 8, and (3) a mesoporous $\mathrm{TiO}_{2}$ layer produced by the high temperature $\left(450{ }^{\circ} \mathrm{C}\right)$ sintering of a $\mathrm{TiO}_{2}$ paste (nanoxide-T, Solaronix) deposited by the doctor blade technique. The freshly prepared films were immersed into a $3 \times 10^{-4} M$ solution of a recently developed hybridized dye ${ }^{9}$ HRS-1, cis-Ru[4, 4' -di(hexythinelvinyl)-2, 2' -bipyridyl] $\left(4,4^{\prime}\right.$-dicarboxylic acid-2, 2'-bipyridyl)(NCS) ${ }_{2}$ (chemical structure is displayed in Fig. 4), in 50:50 mixture of acetonitrile (AN) and tert-butanol by volume for $20 \mathrm{~h}$ at room

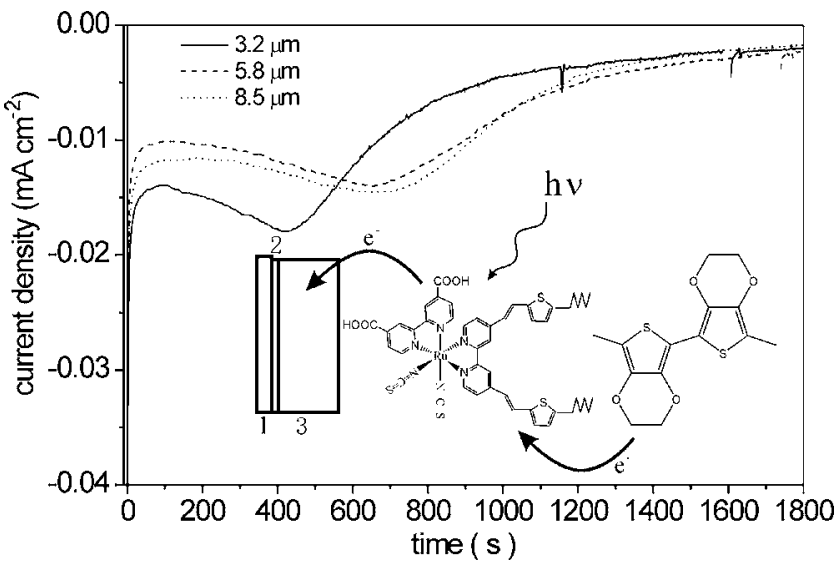

FIG. 1. Current density vs time recorded during the photoelectrochemical polymerization of bis-EDOT. The device structure and the polymerization process are schematically illustrated in the inset. 
temperature. The substrates were then immersed into a solution of $0.1 M \mathrm{LiClO}_{4}$ and $0.01 \mathrm{M}$ bis-EDOT in AN and illuminated from the mesoporous $\mathrm{TiO}_{2}$ side by a $500 \mathrm{~W}$ Xe lamp $\left(22 \mathrm{~mW} \mathrm{~cm}^{-2}, \lambda>500 \mathrm{~nm}\right)$. The polymerization was carried out under potentiostatic conditions in a threeelectrode one-compartment electrochemical cell using the dye-adsorbed $\mathrm{TiO}_{2}$ substrate as the working electrode, $\mathrm{Pt}$ wire as the counterelectrode, and $\mathrm{Ag} / \mathrm{AgCl}$ as the reference electrode. A constant $0.2 \mathrm{~V}$ vs $\mathrm{Ag} / \mathrm{AgCl}$ was applied for $30 \mathrm{~min}$, and the current was monitored by an electrochemical analyzer (BAS 100B). After polymerization, the films were rinsed with AN and treated with 1-ethyl-3methylimidazolium bis-(triflouromethanesulfone)amide containing $0.2 \mathrm{M}$ lithium bis-(trifluoromethanesulfone)amide and $0.2 M$ 4-tert-butylpyridine for $24 \mathrm{~h}^{10}$ The sandwich-type devices were finished by clipping a Au sputtered counterelectrode.

The recorded current traces during photoelectrochemical polymerization of bis-EDOT using dye-coated $\mathrm{TiO}_{2}$ films are shown in Fig. 1. After an initial spike, the current under constant $22 \mathrm{~mW} \mathrm{~cm}{ }^{-2}$ illumination increases and reaches its maximum after $420 \mathrm{~s}$ if $d=3.2 \mu \mathrm{m}$, and $660 \mathrm{~s}$ if $d=5.8 \mu \mathrm{m}$ and $d=8.5 \mu \mathrm{m}$, respectively, where $d$ is the thickness of the mesoporous $\mathrm{TiO}_{2}$ film. Interestingly, the total polymerization charge $\left(\sim 15 \mathrm{mC} \mathrm{cm}^{-2}\right)$ changes within only a few percent by changing the $\mathrm{TiO}_{2}$ layer thickness.

Four devices with active areas between 0.15 and $0.35 \mathrm{~cm}^{-2}$ have been fabricated in each polymerization run, and the mean value (solid squares), standard deviation (boxes), and minimum and maximum values (crosses) of the photovoltaic parameters obtained for 8-12 devices for each $\mathrm{TiO}_{2}$ film thickness are shown in Fig. 2. The current densityvoltage curves were recorded under $100 \mathrm{~mW} \mathrm{~cm}^{-2}$ solar simulator illumination (air mass 1.5, Yamashita Denso YSS80). All devices were prepared and characterized on air without any sealing. The measured short circuit current reaches the highest value (on average $4.5 \mathrm{~mA} \mathrm{~cm}^{-2}$ ) when the $\mathrm{TiO}_{2}$ layer is $5.8 \mu \mathrm{m}$. Remarkably, the fill factor increases significantly by increasing the $\mathrm{TiO}_{2}$ thickness up to $5.8 \mu \mathrm{m}$. The open circuit voltage, on the other hand, varies only slightly with the $\mathrm{TiO}_{2}$ thickness. In summary, the highest power conversion efficiency of $2.6 \%$ (average of ten samples is around $2.1 \%$ ) is achieved when the $\mathrm{TiO}_{2}$ layer is $5.8 \mu \mathrm{m}$.

The current density-voltage curves measured for a device with $5.8 \mu \mathrm{m} \mathrm{TiO}_{2}$ layer at various illumination intensities (attenuated by neutral density filters) is shown in Fig. 3. The photovoltaic parameters are plotted versus the light intensity in the inset. A linear light intensity dependence of the short circuit current is observed. The maximum efficiency of these devices is reached at the highest measured light intensities.

The power conversion efficiency is mainly limited by the small short circuit current $\left(J_{\mathrm{sc}}\right)$. Even though a larger fraction of the incoming photons is absorbed when $d$ is increased, the $J_{\text {sc }}$ increases only slightly. This result indicates incomplete filling of the pores of the $\mathrm{TiO}_{2}$ electrodes. The $\mathrm{TiO}_{2}$ thickness-independent total polymerization charge, which should be directly related to the amount of polymerized PEDOT if only Faradic currents are considered, supports this idea. A possible reason is the blocking of the entrance of the channels of the $\mathrm{TiO}_{2}$ films during the photoelectrochemical polymerization by the growing PEDOT phase, preventing the supply of bis-EDOT deeper into the films. The illumination
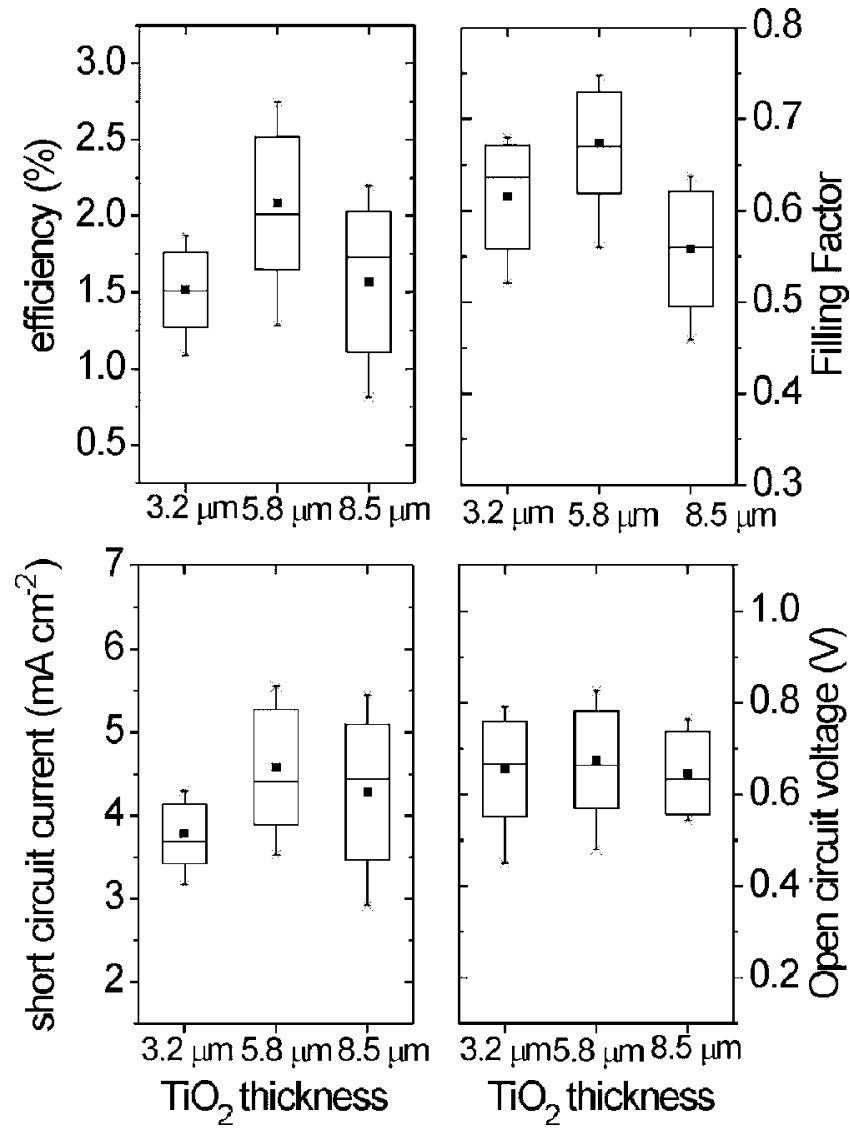

FIG. 2. Photovoltaic parameters averaged for 8-12 DSCs with various thicknesses of the mesoporous $\mathrm{TiO}_{2}$ layer: solid squares, average value; box, standard deviation; and crosses, minimum and maximum values.

during the photoelectrical polymerization enters from the mesoporous $\mathrm{TiO}_{2}$ side, thus we expect that less PEDOT is formed near the FTO contact. We note that attempts to run the polymerization by illuminating from the FTO side (or increasing the light intensity during polymerization) typically leads to decreased $V_{\text {oc }}$ and FF. ${ }^{11}$ Although the incomplete filling of the pores leaves a fraction of the photosensitizer molecules uncovered, reducing the short circuit current,

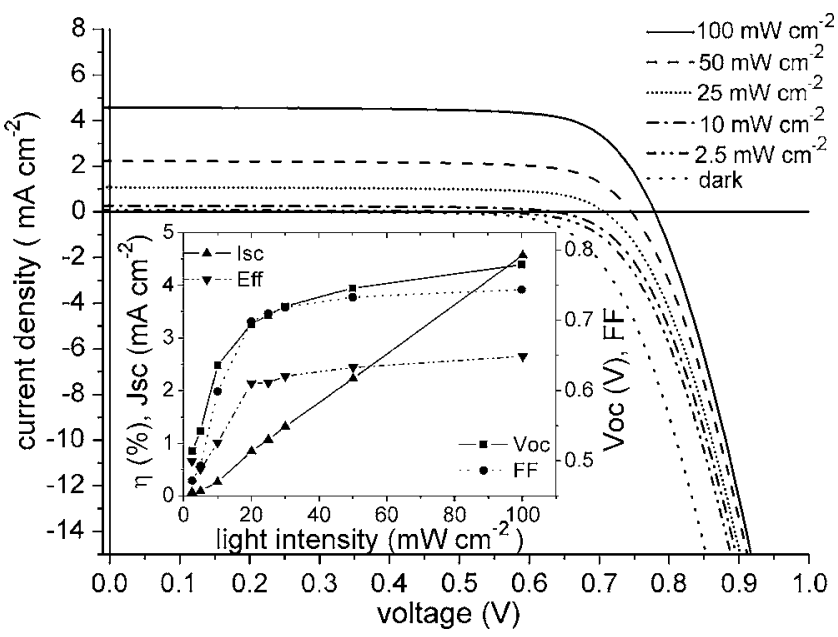

FIG. 3. Current density vs voltage curves at various light intensities of a DSC using photoelectrochemically deposited PEDOT. $\mathrm{TiO}_{2}$ layer thickness is $5.8 \mu \mathrm{m}$. The inset shows the light intensity dependence of the short circuit current $\left(I_{s c}\right)$, open circuit voltage $\left(V_{\circ}\right)$, filling factor (FF), and power conversion efficiency $(n)$. 


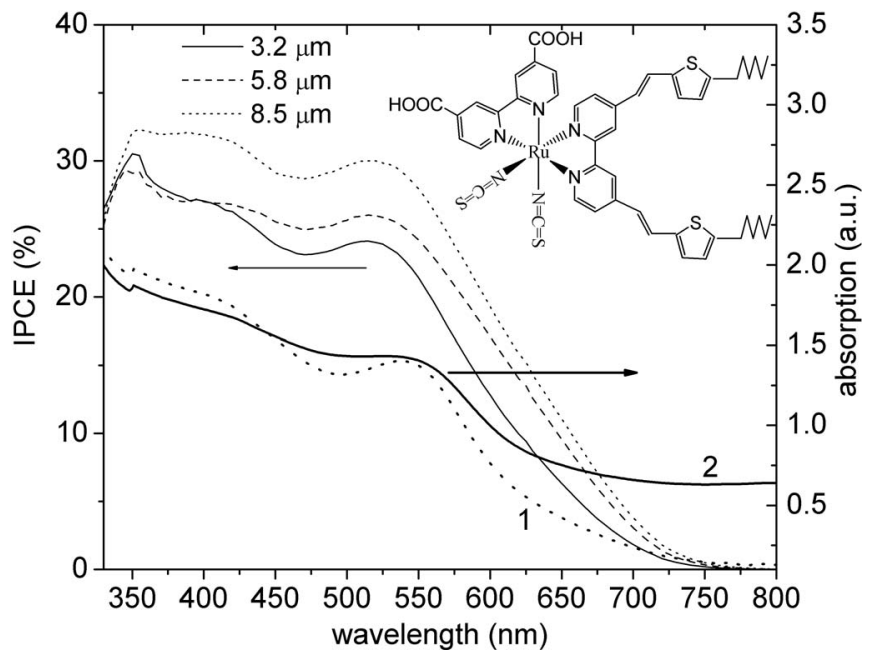

FIG. 4. Absorption of dye-immersed $\mathrm{TiO}_{2}$ films (1) before and (2) after PEDOT deposition. The incident photon to collected electron spectra measured for various $\mathrm{TiO}_{2}$ layer thicknesses are also displayed.

the lower amount of PEDOT near the FTO interface may improve the rectification of our devices, leading to high fill factors of up to 0.74 . The above demonstrates that the ability to control the light intensity distribution within the dyecoated $\mathrm{TiO}_{2}$ films during the photopolymerization process offers additional flexibility as compared to other methods that normally rely on capillary forces or gravity.

An additional effect leading to lower photocurrent could be an optical filtering effect of the PEDOT. Figure 4 shows the absorbance of dye covered $\mathrm{TiO}_{2}$ films (1) before and (2) after PEDOT deposition (calculated from transmission measurements by illuminating from the FTO side and not corrected for reflectance). A broad absorption band $\lambda$ $>600 \mathrm{~nm}$ appears after PEDOT deposition, characteristic of a $p$-doped PEDOT film. From the incident photon to con- verted electron spectra determined by a commercial setup (PV-25DYE, Bunkoh Keiki Co.) it is evident that the additional absorption by PEDOT (especially $\lambda>700 \mathrm{~nm}$ ) does not contribute to noticeable photocurrent, limiting the power conversion efficiency.

In summary, DSCs employing a hybridized ruthenium dye and PEDOT reaching a maximum power conversion efficiency of $2.6 \%$ have been produced and characterized. The best performance is achieved when the mesoporous $\mathrm{TiO}_{2}$ layer is $5.8 \mu \mathrm{m}$. It is demonstrated that developing hybridized photosensitizers with improved chemical compatibility with hole conducting polymers is a viable way towards high performance and cost effective solid state photovoltaic applications.

One of the authors (A.J.M.) acknowledges the financial support of the Japanese Society for the Promotion of Science.

${ }^{1}$ B. O'Regan and M. Grätzel, Nature (London) 353, 737 (1991).

${ }^{2}$ M. Matsumoto, H. Miyazaki, K. Matsuhiro, Y. Kumashiro, and Y. Takaoka, Solid State Ionics 89, 263 (1996).

${ }^{3}$ N. Papageorgiu, Y. Athanassov, M. Armand, P. Bonhôte, H. Pettersson, A. Azam, and M. Grätzel, J. Electrochem. Soc. 143, 3009 (1996).

${ }^{4}$ N. Yamanaka, R. Kawano, W. Kubo, T. Kitamura, Y. Wada, M. Watanabe, and S. Yanagida, Chem. Commun. (Cambridge) 6, 740 (2005).

${ }^{5}$ L. Schmidt-Mende and M. Grätzel, Thin Solid Films 500, 296 (2006).

${ }^{6}$ K. Murakoshi, R. Kogure, Y. Wada, and S. Yanagida, Chem. Lett. 1997, 471.

${ }^{7}$ L. Schmidt-Mende, S. M. Zakeeruddin, and M. Grätzel, Appl. Phys. Lett. 86, 013504 (2005).

${ }^{8}$ Y. Saito, N. Fukuri, G. K. R. Senadeera, T. Kitamura, Y. Wada, and S. Yanagida, Electrochem. Commun. 6, 71 (2004).

${ }^{9}$ K.-J. Jiang, N. Masaki, J.-B. Xia, S. Noda, and S. Yanagida, Chem. Commun. (Cambridge), 23, 2460 (2006).

${ }^{10}$ Y. Saito, T. Kitamura, Y. Wada, and S. Yanagida, Synth. Met. 131, 185 (2002).

${ }^{11}$ N. Fukuri, N. Masaki, T. Kitamura, Y. Wada, and S. Yanagida (unpublished). 